\title{
High-Resolution Temperature Datasets in Portugal from a Geostatistical Approach: Variability and Extremes $\mathscr{O}$
}

\author{
A. R. FOnSECA AND J. A. SANTOS \\ Centre for the Research and Technology of Agro-Environmental and Biological Sciences, Universidade \\ de Trás-os-Montes e Alto Douro, Vila Real, Portugal
}

(Manuscript received 30 July 2017, in final form 7 December 2017)

\begin{abstract}
Climate research in Portugal is often constrained by the lack of homogeneous, temporally and spatially consistent, and long-term climatic series. To overcome this limitation, the authors developed new highresolution gridded datasets $(\sim 1 \mathrm{~km})$ of daily mean, minimum, and maximum air temperatures over Portugal (1950-2015, 66 yr), based on gridded daily temperatures (E-OBS) at $\sim 25-\mathrm{km}$ spatial resolution. A two-step approach was followed, under the assumption that daily temperature variability in Portugal is mainly controlled by atmospheric large-scale forcing, while local processes are mostly expressed as strong spatial gradients. First, monthly baseline (1971-2000) patterns were estimated at 1-km grid resolution by applying multivariate linear regressions (exploratory variables: elevation, latitude, and distance to coastline). A kriging of residuals from baseline normals of 36 weather stations was applied for bias corrections. Second, bilinearly interpolated daily temperature anomalies were then added to the daily baseline patterns to obtain the final datasets. The method performance was evaluated using fivefold cross-validations. The datasets were also validated using daily temperatures from 23 stations not incorporated in E-OBS. A climatological analysis based on these datasets was carried out, highlighting spatial heterogeneities, seasonality, long-term trends, interannual variability, and extremes. The spatial and temporal variability is generally coherent with previous studies at coarser resolutions. An overall warming trend is apparent for all variables and indices, but showing different strengths and spatial variability. These datasets show important advantages over preexisting data, including more detailed and accurate information on trends and interannual variability of precipitation extremes, and can thus be applied to several areas of research in Portugal, such as hydrology, ecology, agriculture, and forestry.
\end{abstract}

\section{Introduction}

In many regions worldwide, the study of temperature variability, including its extremes, is often restricted by the lack of high-resolution gridded datasets at daily time scales and available over sufficiently long-time periods (at least 30 years according to the recommendations of the World Meteorological Organization). There have been many contributions over the last years to overcome these limitations by generating high-resolution and world-based gridded datasets, including those based on relationships between a given predictand and geographic parameters (geostatistical approaches), such as

Supplemental information related to this paper is available at the Journals Online website: https://doi.org/10/1175/JAMC-D-170215.s1.

Corresponding author: André Fonseca, andre.fonseca@utad.pt latitude, longitude, and elevation (Di Luzio et al. 2008; Harris et al. 2014; Hijmans et al. 2005; New et al. 2002; Schamm et al. 2014).

In the specific case of Portugal, several previous studies have demonstrated the key role played by the large-scale atmospheric circulation on temperature variability and corresponding extremes (Andrade et al. 2012, 2014; Santos et al. 2015b; Santos and Corte-Real 2006). These previous studies demonstrated that the temporal variability of temperature over mainland Portugal is strongly governed by large-scale forcing, even on a daily time scale, which implies that the daily temperature anomalies (departures from their long-term means) tend to have high spatial coherency throughout the country. However, the complex orography, the distance to the coastline, and latitudinal variation in the transition between the climatological Azores high and subpolar Icelandic low pressure systems, among other drivers, significantly enhance regional differences. These features underlie the strong 
spatial gradients in the temperature fields over the country (Costa et al. 2017), highlighting the importance of having high-resolution datasets for regional-to-local scale assessments (e.g., at a river basin scale).

The E-OBS daily gridded dataset is currently available over mainland Portugal (Haylock et al. 2008), but at a relatively coarse grid resolution $(\sim 25 \mathrm{~km})$, which is an important shortcoming for many climate research studies and applications to hydrology, ecology, environment, or energy, among others. Weather forecast model runs, with assimilation of observational data, such as in the ERAInterim reanalysis (Dee et al. 2011), are a widely used tool to overcome the lack of observational atmospheric data, since models are able to interpolate observations in a dynamically coherent manner (Washington and Parkinson 2005). Nonetheless, the resolutions of global models are typically very coarse $(\sim 100 \mathrm{~km})$ and are thereby not suitable for risk assessments at local or regional scales (Solman 2013). Therefore, downscaling techniques are of great importance because of their potential to resolve spatial and temporal variability of meteorological variables ( $\mathrm{Li}$ et al. 2010; Monteiro-Henriques et al. 2016).

Dynamical downscaling is based on regional climate models, nested on global climate models through a succession of limited domains with increasing spatial resolutions. On the other hand, statistical downscaling is a lower computationally demanding technique, based on empirical statistical relationships between large-scale variables (predictors) and local variables (predictands) (Ahmed et al. 2015; Chu et al. 2008; Giorgi and Mearns 1999; Laflamme et al. 2016; Menzel and Bürger 2002). The application of a suitable statistical downscaling method may be dictated by site-specific conditions and by the target variables. In effect, considerable differences in the downscaled parameters/variables can be attained by applying different downscaling methods (Dobler et al. 2012; Graham et al. 2007; Gutiérrez et al. 2013; Lenderink et al. 2007; Maraun et al. 2010). Other important limiting factors should also be considered, such as the choice of the predictors, which should provide meaningful statistical relationships with the predictands, including under climate change scenarios (Frias et al. 2006; Vrac et al. 2007). According to Giorgi and Mearns (1999), the downscaling methods should preferably include regional predictands, although the extent of their geographical domain largely depends on the predictor, time scale, and atmospheric circulation patterns controlling the predictor, among other factors.

Geostatistical approaches, using interpolation methods on geographical parameters, can be used to downscale atmospheric variables. Geographical parameters such as elevation (Price et al. 2000; Willmott and Robeson 1995) or distance to coastline (Daly et al. 2002) are strong candidates as exploratory variables in these methodologies. Different interpolation methods can be used for this purpose. Depending on the specific variables being analyzed and on the study motivation, the interpolation method is usually a user choice, often supported by different performance metrics, field observations, and empirical knowledge of the spatial distribution of a given predictor. For instance, the inverse distance weighting interpolation is largely applied in many areas of research, but tends to generate so-called bull's eyes patterns (De Smith et al. 2007). On the other hand, kriging and cokriging methods, more computationally demanding, are widely used in climatology (Schuurmans et al. 2007). For monthly and yearly climatic variables, polynomial functions, including spline techniques, are also quite recurrent interpolation methods (Laslett 1994).

The performance of the different downscaling approaches must be tested, particularly when accurate information is required, such as for impact assessments on hydrologic systems (Beldring et al. 2008; Chen et al. 2013; Dobler et al. 2012). A $k$-fold cross-validation is generally recommended to properly evaluate the method performance (Gutiérrez et al. 2013). In climate research, for a better assessment of the performance of a given dataset, it is also common to analyze the consistency of climatic indices estimated from the dataset with those directly derived from observations (Maraun et al. 2015; Martin-Vide 2004; Merino et al. 2016).

The aims of the present study are 1) to develop a new high-resolution dataset ( $\sim 1-\mathrm{km}$ spatial resolution) of daily mean, minimum, and maximum air temperatures over mainland Portugal, based on existing coarser-resolution gridded observational datasets (E-OBS) and following a geostatistical/interpolation approach, and 2) to assess the spatial and temporal variability of temperature and of its extremes over Portugal at the $1-\mathrm{km}$ spatial resolution. A high-resolution dataset is herein produced based on coarser-resolution observational gridded data. Although the generation of these datasets should be preferably based on original weather station records, the present study approach is suitable for regions with low-density weather station networks, important data gaps, and inhomogeneities, such as in Portugal. The manuscript is structured as follows: in section 2 the datasets and the applied methodologies will be described. The main results are presented and discussed in section 3 , and the conclusions are outlined in section 4.

\section{Materials and methods}

\section{a. Dataset development}

Observation-based gridded datasets of daily mean (TG), minimum (TN), and maximum (TX) air 
temperatures are used in this study as a basis for the dataset development. They were retrieved from the E-OBS project, version 15.0 (Haylock et al. 2008). These datasets provide continuous and homogeneous information throughout Europe, despite the documented limitations (Hofstra et al. 2009). Data for the period of 1950-2015 (target period of the present study, 66 years), available on an $\sim 25$-km spatial resolution, were extracted for grid boxes over mainland Portugal. Other databases are available at a higher resolution over Portugal, but only monthly long-term means (Hijmans et al. 2005) or daily estimates based on monthly time series from weather stations (Ninyerola et al. 2005) are available, thus limiting their representativeness of the Portuguese climatic conditions. Therefore, the E-OBS datasets are the best available source of temperature data over Portugal on the daily time scale and over a relatively long time period (starting in 1950). As only a few available weather stations over Portugal have homogeneous and uninterrupted (few or no data gaps) temperature records within the target period ( $<10$ stations), the methodology followed in the present study was based on the E-OBS gridded dataset rather than on the weather stations series. For the E-OBS datasets, station data were already subjected to preliminary quality control and data gaps were filled in by gridding procedures, thus being preferable than using station data directly.

As previously mentioned, the dataset development is based on the assumption that the interday temperature variability in Portugal is mainly governed by large-scale atmospheric forcing, thus having a strong spatial coherency. This implies that the E-OBS gridded daily temperature anomalies (departures from their long-term means at each grid point), defined at the $\sim 25-\mathrm{km}$ grid resolution, are already able to capture the bulk of the temporal variability of temperatures in Portugal on the daily time scale. Conversely, the signature of the local processes is mostly apparent on the spatial variability of temperature (microclimates), which can be effectively captured by geostatistical approaches. Therefore, a two-step approach is followed herein: 1) geostatistical interpolation of temperatures for capturing daily mean spatial variability and 2) bilinear interpolation of daily temperature anomalies for capturing temporal variability. The final datasets are obtained by adding these two components (spatial and temporal variability). This general assumption will be tested below by using method performance measures.

Figure 1 outlines the steps followed to obtain the highresolution temperature datasets. First, a preliminary bilinear interpolation (in the latitude $\times$ longitude grid) was applied to interpolate the E-OBS daily fields from the original grid $(\sim 25 \mathrm{~km})$ to an $\sim 1-\mathrm{km}$ grid (Fig. 1). Second, to properly resolve the spatial variability of temperature, multiyear monthly means (from January to December and over the reference period of 1971-2000) were computed from the daily bilinearly interpolated temperatures (right-hand side of Fig. 1). The resulting monthly patterns were subsequently subject to ordinary least squares (OLS) linear regressions with three explanatory variables: latitude, Euclidean distance to the coastline, and elevation (at $\sim 1-\mathrm{km}$ resolution). New multiyear monthly mean temperature patterns (monthly baselines henceforth), also at $\sim 1-\mathrm{km}$ grid resolution, but with much higher spatial details, were then attained (Fig. 1). The $R^{2}$ values (determination coefficients) from OLS are, for all months, $\geq 91 \%$ in $\mathrm{TG}, \geq 85 \%$ in $\mathrm{TN}$, and $\geq 87 \%$ in $\mathrm{TX}$ (see Table $\mathrm{S} 1$ in the online supplemental material). The corresponding analyses of variance (ANOVA) revealed statistically significant models, according to the $F$ test at $1 \%$ significance level. Although the relevance of each regressor (latitude, elevation, and distance to coastline) depends on the variable and month (e.g., the distance to coastline is particularly important in the summer months), the three regressors are statistically significant for the three variables (TG, TN, and TX) and for all months, according to the Student's $t$ test at 5\% significance level (cf. corresponding $95 \%$ confidence intervals in supplemental Table S2). The regressor coefficients are negative for both latitude (negative meridional temperature gradients in the Northern Hemisphere) and elevation (negative vertical temperature gradients in the troposphere), in agreement with climatology (Peixoto and Oort 1992). The regressor coefficients for the distance to coastline have negative (positive) values for the winter (summer) half of the year, thus highlighting a general cooling (warming) trend in winter (summer) as the distance to the coast increases. Similar geostatistical procedures were already applied in previous studies (Di Luzio et al. 2008; Harris et al. 2014; Hijmans et al. 2005; New et al. 2002; Ninyerola et al. 2005; Schamm et al. 2014).

Although the OLS-derived temperature patterns already provide detailed information on high spatial resolution $(\sim 1 \mathrm{~km})$, other factors than the exploratory variables (e.g., land cover properties, breezes, and other mesoscale systems) may also influence local temperatures, leading to biases between the interpolated and the observed temperatures. Aiming at improving the correspondence between the above-described monthly baselines and observations, bias corrections were thus undertaken based on long-term monthly mean temperatures for a network of 36 meteorological stations in 


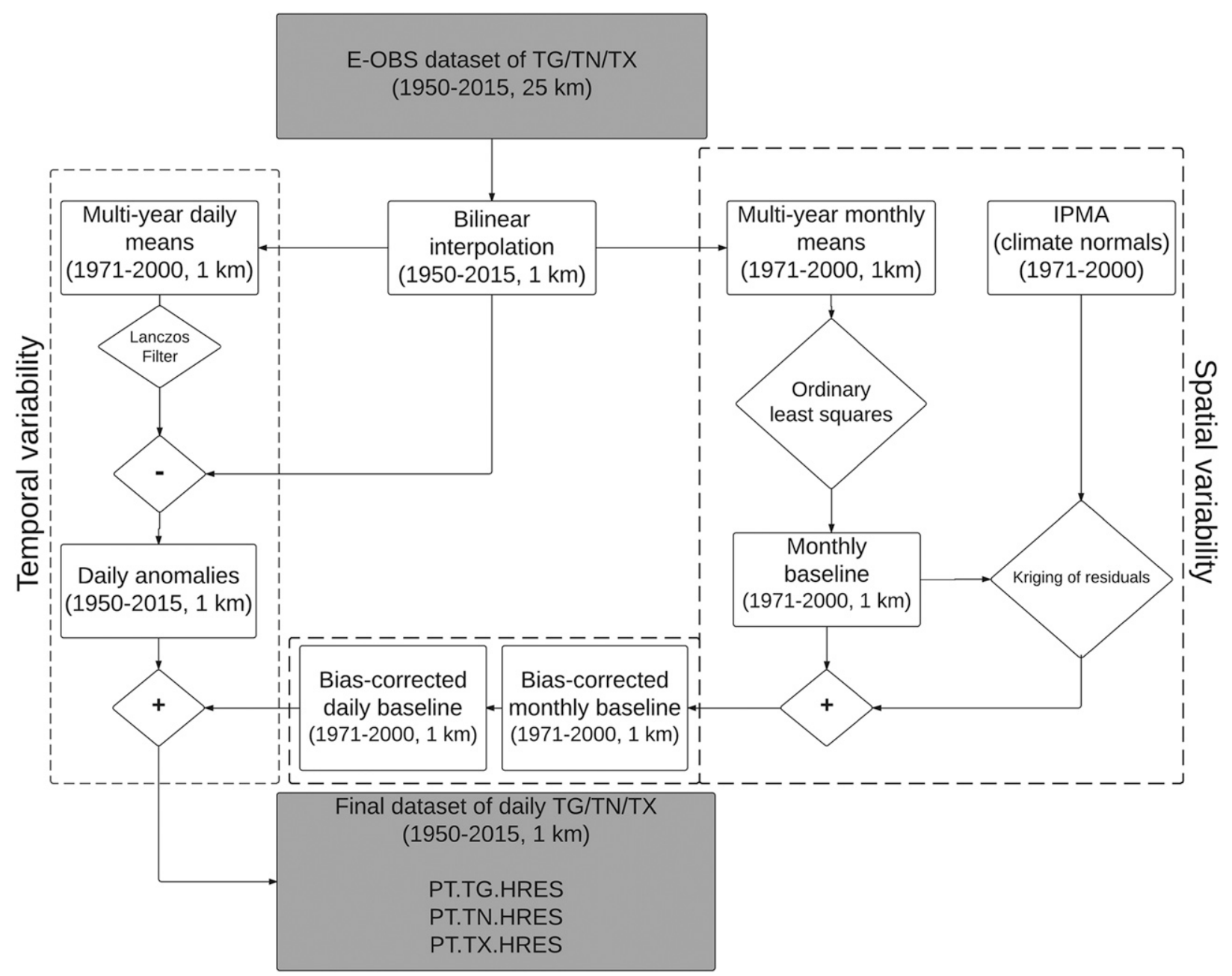

FIG. 1. Flowchart of the methodology used for the development of the high-resolution daily mean, maximum, and minimum temperature datasets over mainland Portugal, i.e., PT.TG.HRES, PT.TX.HRES, and PT.TN.HRES, respectively. The modules for the resolution of (left) temporal and (right) spatial variability are indicated by dashed lines (see text for details).

Portugal (Fig. 2) and defined over the same reference period of 1971-2000 (Fig. 1). These stations cover the full range of elevation over mainland Portugal, since temperature gradients are not always uniform over large elevation ranges (Table S3 in the online supplemental material). Further, of all the 36 stations considered, 23 stations are not used in the E-OBS dataset (only 13 were used to generate this dataset). Monthly baselines were considered instead of daily baselines, since only monthly baseline normals are available. Station data were supplied by the Portuguese Weather Service (IPMA; http:// www.ipma.pt). A kriging interpolation (i.e., Gaussian process regression) of the biases (residuals) to the $1-\mathrm{km}$ grid was then added to the corresponding monthly baseline (hereinafter bias-corrected monthly baselines; Fig. 1). The semivariogram parameters from the kriging of the residuals are shown in supplemental Table S4.
The corresponding semivariograms are also shown in supplemental Figs. S7-S9. A temporal linear interpolation of these monthly patterns was then applied to obtain the daily baseline patterns (Fig. 1), thus resolving spatial variability on the daily time scale. Spline and polynomial interpolations were also tested, but the results were very similar and the linear (simplest) method was eventually chosen.

As previously mentioned, daily temperature anomalies are largely controlled by large-scale atmospheric forcing and thus tend to be spatially coherent (e.g., the correlation coefficient between daily mean temperature anomalies in Beja, in the very south, and Bragança, in the very north, is as high as 0.80 for 1950-2015). As such, the E-OBS daily temperature anomalies on the $\sim 25-\mathrm{km}$ grid should already provide a good representation of temporal variability over Portugal. Gridded daily 


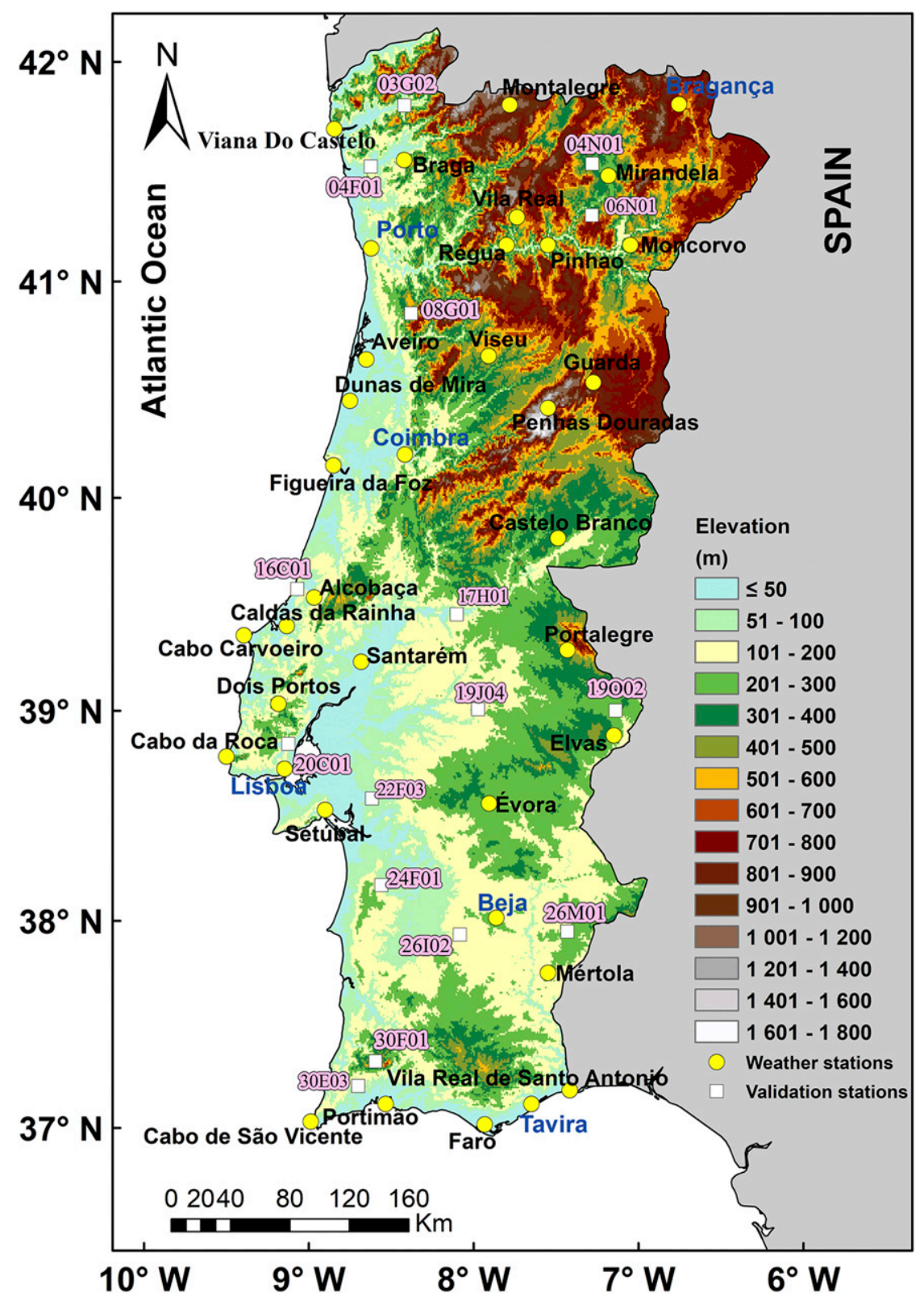

FIG. 2. Elevation (m) map of mainland Portugal. The network of weather stations (yellow circles) used for bias corrections (baseline normals: 1971-2000) is also shown. Bragança, Porto, Coimbra, Lisboa, Beja, and Tavira stations (in blue) were also used for calculating temperature indices (see text for details). The network of 16 weather stations used for validation of the datasets is also indicated (white squares).

anomalies (i.e., departures of daily temperature fields from the corresponding long-term means, for the reference period of 1971-2000) at each grid point, were calculated from the 1-km bilinearly interpolated E-OBS dataset and for 1950-2015 (left-hand side of Fig. 1). Bilinear interpolation preserves the signature of the large-scale forcing, not having other predictors than point distances. To remove high-frequency noise from the seasonal cycle, the long-term daily means were smoothed out by a low-pass Lanczos filter (Duchon 1979), with cutoff frequency at 30 days and 500 coefficients. Last, the gridded daily anomalies for the full period of 1950-2015 were added to the corresponding calendar daily baseline patterns to reconstruct the daily temperature patterns. The aforementioned procedure was fully repeated for the three climatic datasets: TG, 
$\mathrm{TN}$, and TX. The resulting very high-resolution gridded temperature datasets are herein named PT.TG.HRES, PT.TN.HRES, and PT.TX.HRES, respectively.

\section{b. Dataset analysis}

A climatological analysis was carried out on the new datasets at the $\sim 1-\mathrm{km}$ grid (PT.TG.HRES, PT.TN.HRES, and PT.TX.HRES). Nine temperature indices were used in this analysis (CDO 2015; Klein Tank and Können 2003): $\mathrm{TGa}=$ mean temperature interannual average; $\mathrm{TNa}=$ minimum temperature interannual average; $\mathrm{TXa}=$ maximum temperature interannual average; $\mathrm{TNn}=$ minimum temperature interannual minimum; $\mathrm{TXx}=$ maximum temperature interannual maximum; $\mathrm{SU}=$ summer days (daily maximum temperature $\geq$ $25^{\circ} \mathrm{C}$ ); $\mathrm{CSU}=$ consecutive summer days; $\mathrm{FD}=$ frost days (daily minimum temperature $<0^{\circ} \mathrm{C}$ ); and $\mathrm{TR}=$ tropical nights (daily minimum temperature $\geq 20^{\circ} \mathrm{C}$ ). The 10 th and 90th percentiles of daily temperatures were also determined. The spatial and temporal variability of these indices, all of them defined at the annual time scale, were examined, namely their average patterns, interannual standard deviations of linearly detrended datasets, and least squares linear trends.

\section{c. Dataset validation}

To assess the performance of the methodology described in Fig. 1, a cross-validation approach was carried out. A selection of nonoverlapping test sets was followed (Markatou et al. 2005), that is, dividing the data available into five sets (a fivefold cross-validation approach, with $13 \mathrm{yr}$ in each set). A stratified sampling approach was also considered, for which the first test set sample comprised the years of 1950, 1955, 1960, 1965, 1970, 1975, 1980, 1985, 1990, 1995, 2000, 2005, and 2010. The second set comprised the years of 1951, 1956, and so on. For this approach, an $80 \%$ to $20 \%$ balance in training to test data was kept (Gutiérrez et al. 2013). For accuracy validation, the root-mean-square error (RMSE), $R^{2}$, and the percentage difference measures are calculated for all test samples (including their mean).

Additionally, an independent validation of the daily temperatures in the three datasets was carried out using data from 16 meteorological stations not incorporated in E-OBS (Fig. 2). These data are available through the Portuguese National Water Resources Information System website (http://snirh.apambiente.pt). A comparison between the current study datasets and the corresponding WorldClim long-term monthly means (Hijmans et al. 2005) is also conducted.

The correspondence between the previous temperature indices estimated from data at six meteorological stations in Portugal (Beja, Bragança, Coimbra, Lisboa,
Porto, and Tavira; cf. Fig. 2) and from the datasets at the nearest point was also evaluated. These time series were previously homogenized by the European Climate Assessment and Dataset (ECA\&D) project (Klein Tank et al. 2002), which is critical for the reliability and accuracy of temperature indices. The following performance measures were calculated: $R^{2}$ (and corresponding $p$ values), bias (difference between interpolated and observed time series means), and RMSE. The validation was not only focused on means but also on extreme values, thus warranting a deeper assessment of the performance of the datasets in replicating the full empirical distributions of the observed temperatures at key meteorological stations in Portugal.

\section{Results and discussion}

\section{a. Mean patterns of temperature in Portugal}

The annual mean temperature over mainland Portugal (PT.TG.HRES) for the period of 1950-2015 ranges from $7.9^{\circ} \mathrm{C}$ at the highest mountain peaks to $17.9^{\circ} \mathrm{C}$ along the southern cost (Fig. 3a). The remaining four plots show the mean temperature patterns for the four seasons separately: winter (Fig. 3b), spring (Fig. 3c), summer (Fig. 3d), and autumn (Fig. 3e).

In winter, mean temperatures range from values slightly below $2^{\circ} \mathrm{C}$ in the highest mountain peaks of central Portugal to $\sim 13^{\circ} \mathrm{C}$ in some locations along the southernmost coast (Fig. 3b). Further, mean temperatures $<5^{\circ} \mathrm{C}$ are only found in high-elevation areas of inner-northern Portugal. The $10^{\circ} \mathrm{C}$-isotherm is nearly parallel to the western coast, reaching northwestern Portugal. As such, winters in Portugal are typically mild (temperatures below the freezing point are uncommon), apart from some highelevation areas in the inner-northern half of the country.

On the other hand, in summer temperatures depict mean values from approximately $16^{\circ} \mathrm{C}$ up to $25^{\circ} \mathrm{C}$ (Fig. 3d), but temperatures $<18^{\circ} \mathrm{C}$ are largely confined to high-elevation areas, highlighting the prevailing summertime warm conditions, which are characteristic of Mediterranean-type climates. Moreover, much cooler conditions are found along the western coast when compared with the southern part of the country or with the inner Douro Valley. Therefore, the winter-summer contrasts are much weaker along the western Atlanticfacing coast, explained by the relatively high thermal inertia associated with the predominant maritime air masses.

For the intermediate seasons, temperatures vary from roughly $7^{\circ}$ to $18^{\circ} \mathrm{C}$ in spring (Fig. 3c) and from $9^{\circ}$ to $20^{\circ} \mathrm{C}$ in autumn (Fig. 3e), the latter thus being slightly warmer on average. The weaker west-east temperature gradients in spring and autumn relative to winter and 

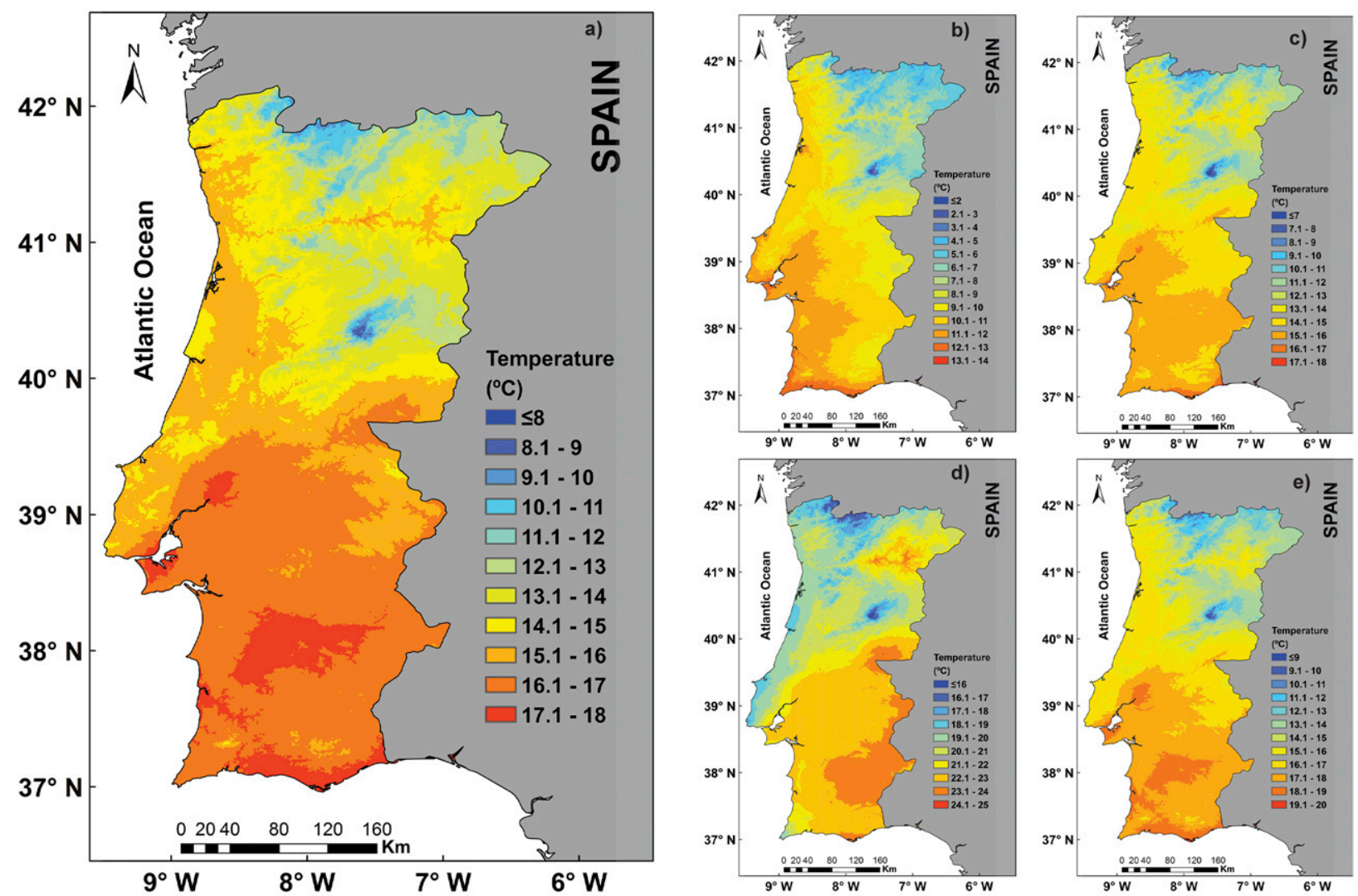

FIG. 3. Downscaled (a) annual, (b) winter, (c) spring, (d) summer, and (e) autumn mean of daily mean air temperature over mainland Portugal for the period of 1950-2015 (PT.TG.HRES; spatial resolution of $\sim 1 \mathrm{~km}$ ).

summer, particularly in the north of Portugal, are still noteworthy, although the north-south gradients remain high. Annual and seasonal patterns for TN and TX were also produced (online supplemental Figs. S1 and S2), showing similar gradients and seasonality, but regional contrasts are enhanced in summertime TX.

\section{b. Spatial and interannual variability}

The patterns of TGa, TNa, and TXa (Figs. 4a,d,g) display the main spatial temperature gradients over Portugal that were already discussed above (section 3a), mostly the decrease of temperatures from the south to the high-elevation areas in the north of the country. Overall, these patterns highlight the strong spatial variability of temperatures over Portugal. Regarding the temporal variability in the period of 1950-2015, the detrended interannual STD patterns of each variable show values in the interval of $0.4^{\circ}-1.2^{\circ} \mathrm{C}$ (Figs. $4 \mathrm{~b}, \mathrm{e}, \mathrm{h}$ ). In addition, $\mathrm{TNa}$ tends to have the highest irregularity, followed by TXa and then TGa. On the whole, the irregularity is maximum in TNa along a strip eastward of Lisbon and in TXa in central-inner Portugal. As expected, the detrended interannual STD pattern for TGa is a combination of the patterns for TNa and TXa. The linear trends show statistically significant (at 99\% confidence level) positive values throughout Portugal (upward trends), mainly in the southwest in $\mathrm{TNa}$ and in the northeast in TXa. In fact, the warming trends are in general agreement with previous studies (Espírito Santo et al. 2014; Lewis and King 2017; Pareeth et al. 2017; Santos et al. 2015a). An analysis of the mechanisms underlying spatial heterogeneity in interannual variability is, however, out of the scope of the present study.

\section{c. Temperature extremes}

As previously mentioned, besides the analysis of mean temperatures, variability, and long-term trends, the examination of temperature extremes is of utmost relevance, owing to the resulting impacts on many environmental and socioeconomic systems. The absolute daily temperature extremes, although very sensitive to observational errors and statistical interpolation methodologies, provide valuable information on thermal thresholds at a given location, which are often critical (e.g., in the distribution of forest species and crops). 

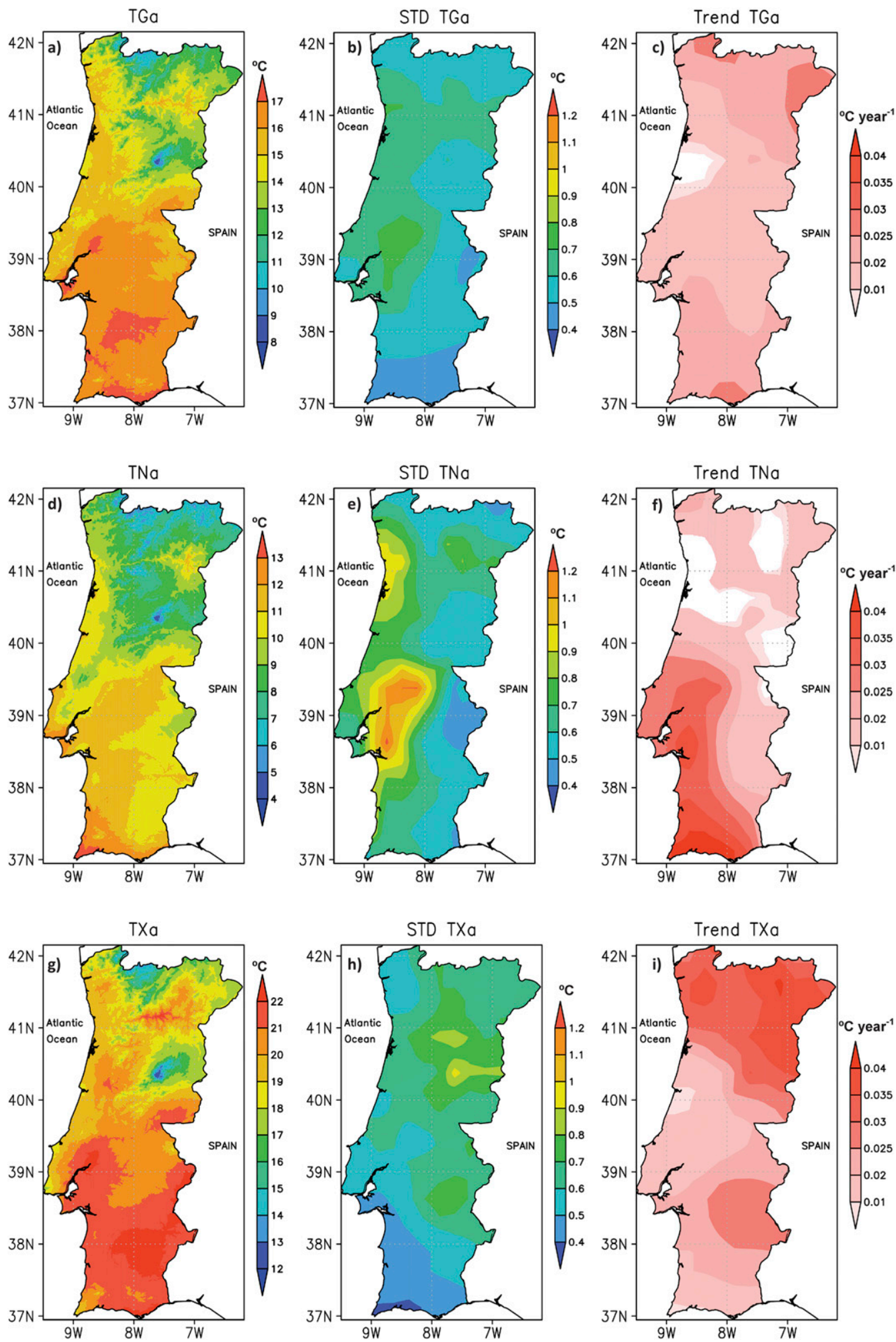

FIG. 4. Spatial and temporal variability of (a)-(c) daily mean (TG), (d)-(f) minimum (TN), and (g)-(i) maximum (TX) temperatures over Portugal: (left) averages (TGa, TNa, and TXa), (center) interannual standard deviations (STD), and (right) least squares linear trends $\left({ }^{\circ} \mathrm{C} \mathrm{yr}^{-1}\right)$. Only trends that are statistically significant at $99 \%$ confidence level are plotted. 

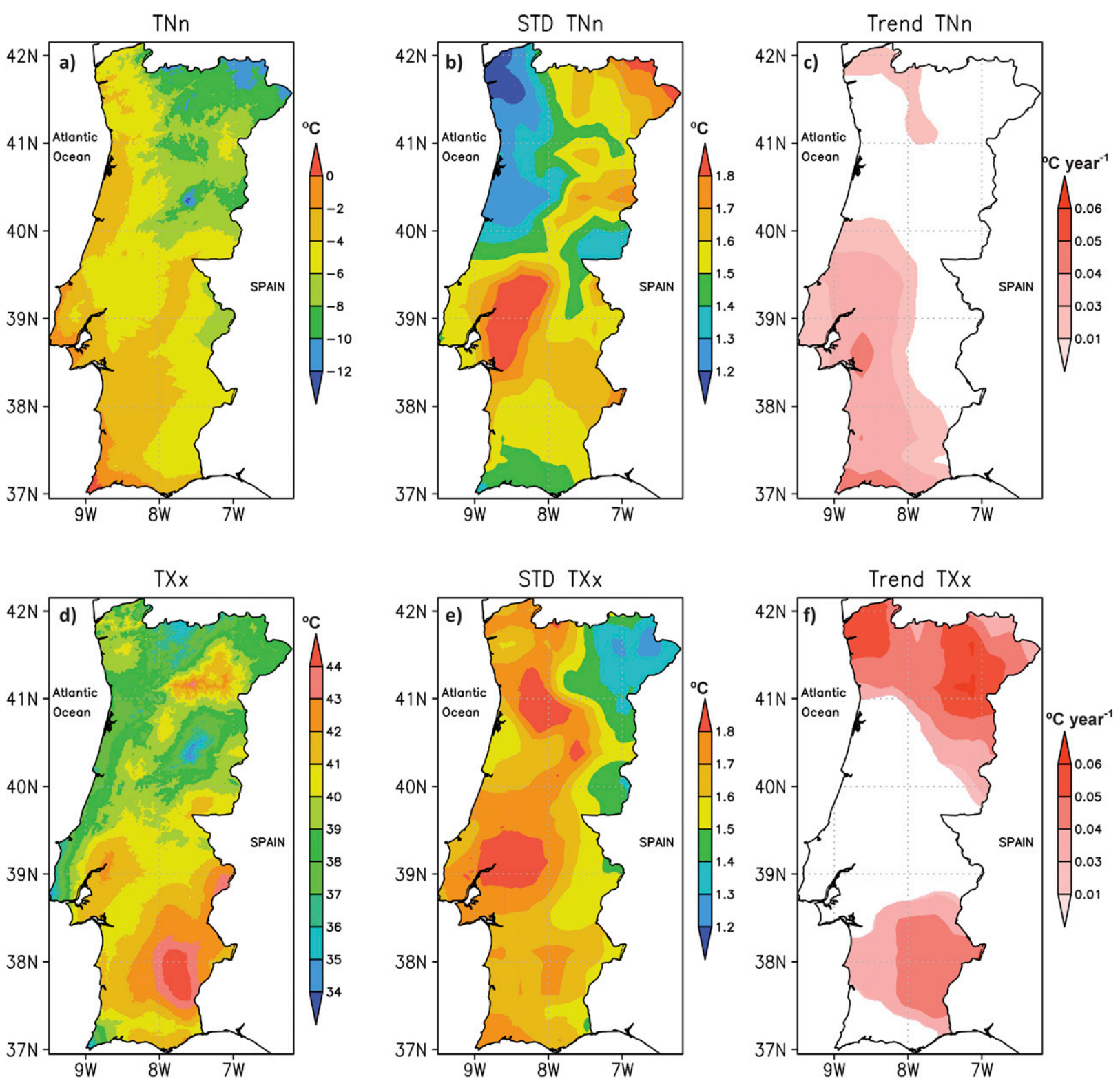

FIG. 5. As in Fig. 4, but for the minimum daily minimum (TNn) and maximum daily maximum (TXx) temperatures.

Of particular interest are TNn and TXx (Fig. 5). TNn ranges from approximately $-12^{\circ} \mathrm{C}$ in Serra-da-Estrela to $0^{\circ} \mathrm{C}$ in the southwestern tip of Portugal (less exposed to cold continental air masses). TXx ranges from about $34^{\circ} \mathrm{C}$ in Serra-da-Estrela and in the westernmost coast of Lisbon to about $44^{\circ} \mathrm{C}$ in inner-southern Portugal. The detrended STD reveals that interannual variability is strongest in the southwest in TNn and over widespread areas in TXx. The warming trends are also statistically significant in the southwest in TNn and in the northnortheast and southeast in TXx, which is also in close agreement with the trends in TNa and TXa (Figs. 5 and 6).
Hence, it can be suggested that the same mechanisms as in $\mathrm{TNa}$ and TXa may underlie the warming trends in TNn and TXx, but a more thorough analysis is required.

The 10th and 90th percentiles of daily temperatures, as well as their departures, are important nonparametric indicators of moderate extremes and variability ranges (Fig. 6). Some general features should be noted in these patterns. Owing to the strong seasonality in temperature, the 10th-percentile patterns mainly reflect wintertime conditions, whereas the 90th-percentile patterns are a manifestation of summertime conditions (Fig. 6). The percentile differences essentially highlight the 

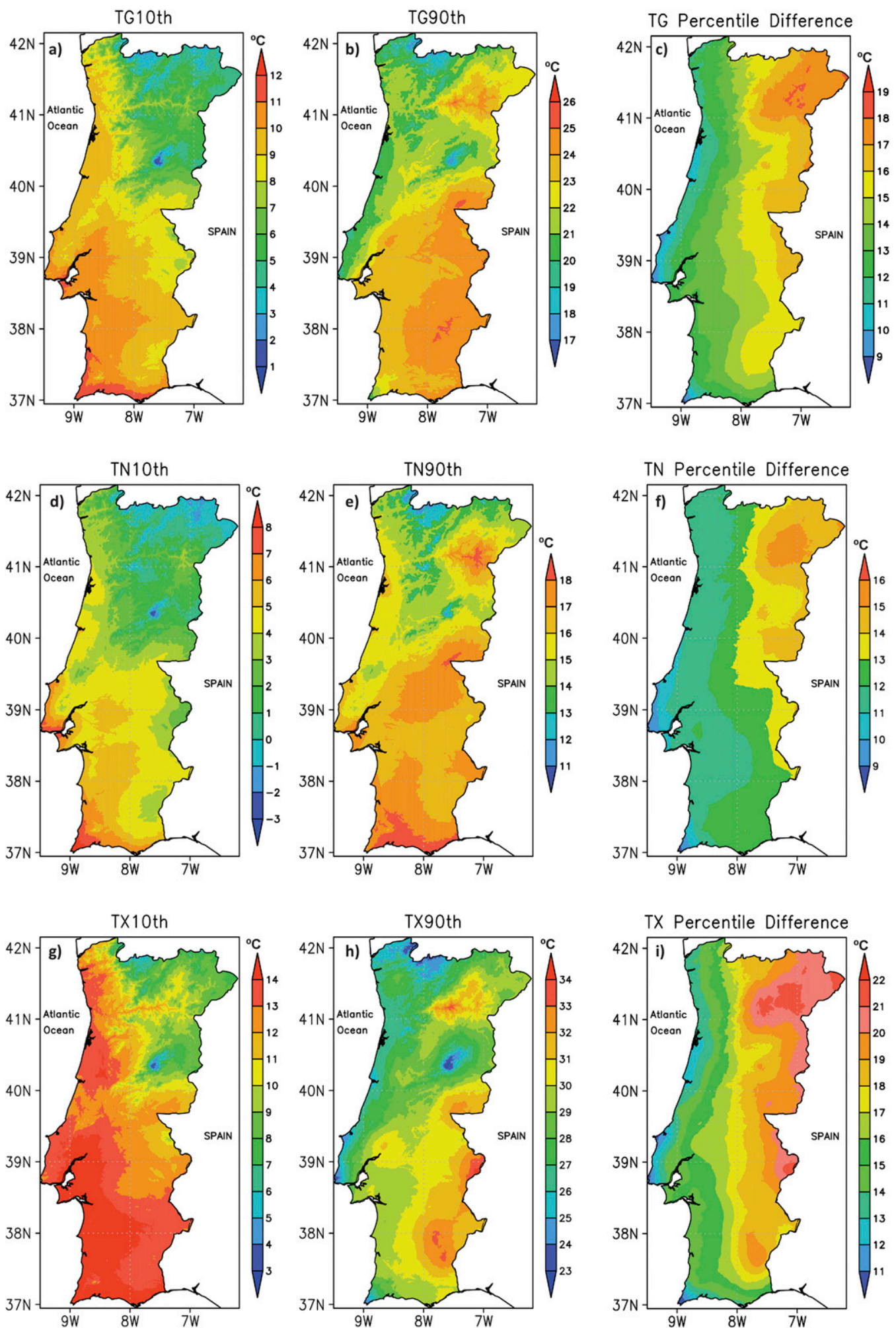

FIG. 6. (left) The 10th and (center) 90th percentiles, and (right) their difference of (top) TG, (middle) TN, and (bottom) TX (daily mean, minimum, and maximum temperatures, respectively) over Portugal. 
continentality effect (distance to the coastline), with much higher values over inner Portugal, mostly in the northeast and in TX, as expected due to the reinforcement of continentality by orographic barriers and by daytime solar radiation fluxes.

The patterns of the four selected predefined temperature extremes (SU, CSU, FD, and TR) were also assessed, as well as their detrended interannual STD and linear trends (Fig. 7). These indices were selected taking into account the main climatic characteristics of Portugal (i.e., largely prevailing Mediterranean-type conditions, with mild winters and warm to hot summers). The number of summer days varies from roughly 20 to 140 , with a clear gradient from the southeast to the northwest, and a pronounced exception in the inner Douro Valley (with a regional secondary maximum). The number of consecutive summer days shows a similar pattern, but with lower values, as expected by definition. However, the only slight decrease from SU to CSU over inner-southern Portugal is remarkable, which means that most of SU occur consecutively in that region (regularly high temperatures). Although the number of frost days ranges from $<10$ to $\sim 90$ in the Serrada-Estrela peak, most of the country experiences values $<20$ days. The number of tropical nights is also relatively low (maximum of $\sim 20$ days), being very rare in the north and along the western-central coastal regions. Very localized maximum occurrences can be found in the inner Douro Valley, in inner-central Portugal and, particularly, in some areas of the southern coast. Strong upward trends in SU and CSU, mostly in the northern half of Portugal; downward trends in FD, very localized over central-western Portugal; and upward trends in TR, especially in the south, hint at a general warming trend over the last decades, which is clearly reflected in the different temperature extremes.

The added value of the present study temperature datasets is clearly illustrated by supplemental Fig. S6, which corresponds to Fig. 7, but directly using the E-OBS dataset, followed by a bilinear interpolation to the same $1-\mathrm{km}$ grid. Although the large-scale spatial features of the extreme temperature indices are generally similar in both approaches, there are significant differences at smaller scales (Fig. 7 vs Fig. S6). For instance, the upper Douro Valley in northeastern Portugal, with a very complex orography, shows much higher values for $\mathrm{SU}$, CSU, and TR in Fig. 7 than in Fig. S6. TR is also underestimated in southern Portugal by E-OBS, particularly along the southern coast. In E-OBS, FD is unrealistically low in high-elevation areas of northern and central Portugal. Similar considerations can be made for other regions throughout Portugal, as well as for the other variables in Figs. 3-6 (not shown). As a result, the corresponding trends and interannual variability of the temperature extreme indices present noteworthy differences between the two approaches (Fig. 7 vs Fig. S6), as these threshold-dependent indices are critically influenced by local biases. Overall, these results hint at the high value of the current datasets relative to preexisting data.

\section{d. Uncertainties and validation}

The dataset development incorporates uncertainties from various error sources. As explained in section 2, an approach based on "local" bias correction, using a network of 36 meteorological stations, is undertaken in order to reduce some of these errors, partly because E-OBS is based on a comparatively small number of meteorological stations over Portugal. Therefore, effective decreases in the RMSE were found from the noncorrected OLS patterns (Table 1) to the final datasets (Fig. 3), which thereby realistically reflect the mean observed temperatures in Portugal. In fact, very low values of RMSE were achieved after bias corrections (TG $\leq$ $0.03^{\circ} \mathrm{C}, \mathrm{TN} \leq 0.93^{\circ} \mathrm{C}$, and $\mathrm{TX} \leq 0.23^{\circ} \mathrm{C}$; Table 1 ).

The fivefold cross-validation performance measures (Fig. 8) were calculated for PT.TG.HRES, PT.TN.HRES, and PT.TX.HRES, on a monthly basis (12 months) and for the 36 meteorological stations (cf. Fig. 2). With regard to the monthly percentage differences (dataset - observations), their absolute values are almost always $<8 \%$, with generally higher values for TN. Absolute median differences are generally in the interval of $2 \%-3 \%$. Negative differences prevail in both TG and TX, showing an overall tendency for a slight underestimation of temperatures in these two datasets. With respect to the $R^{2}$ measure, values $>0.95$ are found for every variable and test, but medians are of $0.97-0.98$. Concerning the RMSE, values are within the $0.4^{\circ}-1.4^{\circ} \mathrm{C}$ range. As no clear differences in the method performance were found between the five tests and the full dataset, it can be stated that overfitting is not an important limitation. Therefore, the previous analyses hint at the good representativeness and robustness of the present study datasets.

Observed and nearest-point estimated daily TG, TN, and TX were compared for 16 meteorological stations in Portugal not incorporated in E-OBS (Table 2). The database is in overall agreement with the observed values at all stations, with statistically significant coefficients of determination ( $99 \%$ confidence level) for all stations and temperatures (TG, TN, and TX). Overall, TG (TN) reveals the highest (lowest) correspondences. The lowest values were found for stations with apparent systematic errors (30F01 and 16C01), owing to factors such as uncalibrated sensors. The low accuracy of 

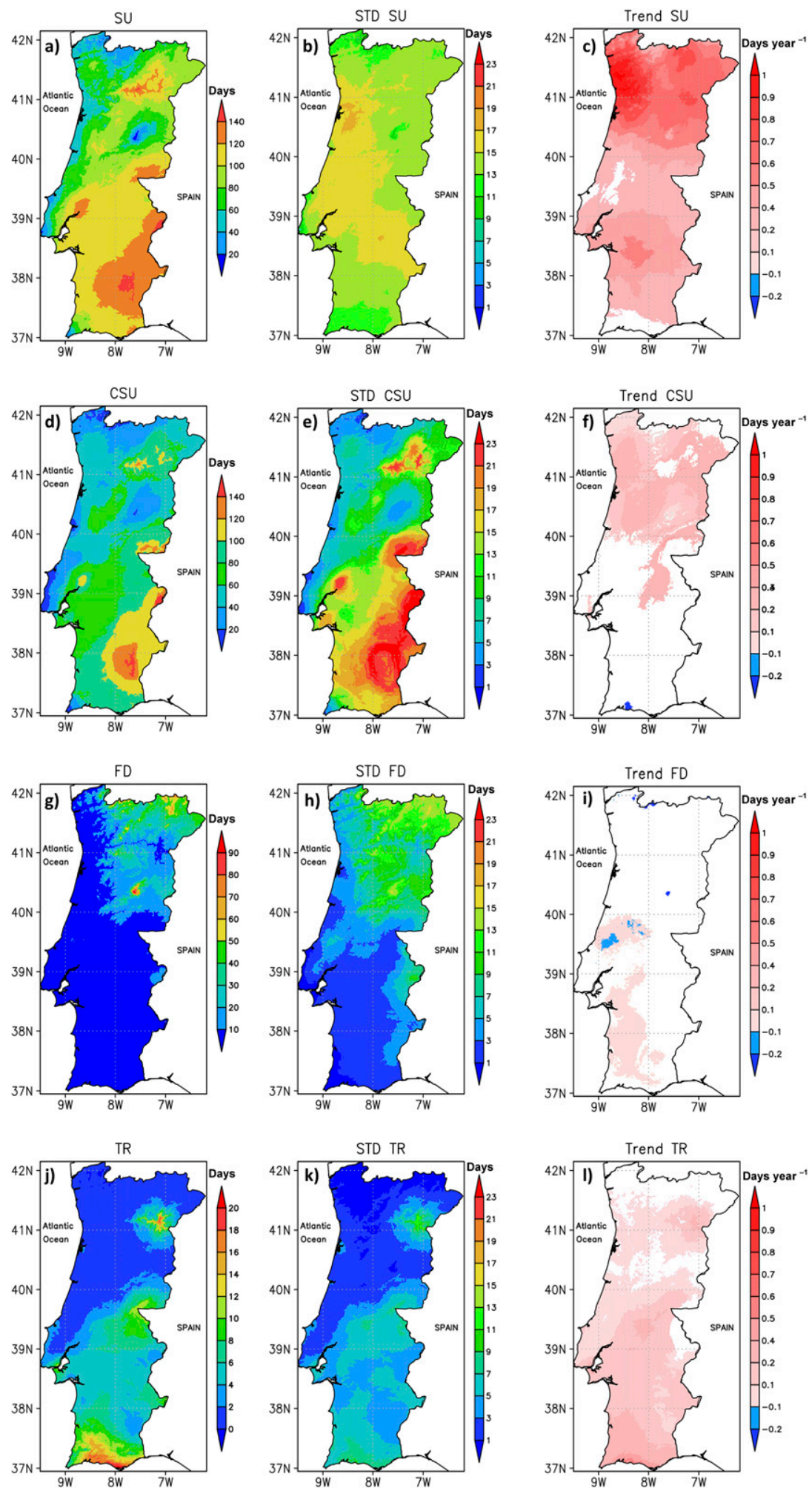

FIG. 7. Temperature extreme indices over Portugal for (a)-(c) SU, (d)-(f) CSU, (g)-(i) FD, and (j)-(l) TR, showing (left) averages, (center) interannual standard deviations, and (right) least squares linear trends (days $\mathrm{yr}^{-1}$ ). Only trends statistically significant at $99 \%$ confidence level are plotted. 
TABLE 1. RMSE for downscaled TG against the observed monthly mean temperatures (1971-2000 baseline) recorded by a network of 36 weather stations over Portugal, using an ordinary least squares multivariate linear regression (OLS) or OLS with a kriging of residuals (KRIG).

\begin{tabular}{ccccccccc}
\hline \hline & \multicolumn{2}{c}{ TG } & & \multicolumn{2}{c}{ TN } & & \multicolumn{2}{c}{ TX } \\
\cline { 2 - 3 } \cline { 8 - 9 } RMSE $\left({ }^{\circ} \mathrm{C}\right)$ & OLS & KRIG & & OLS & KRIG & & OLS & KRIG \\
\hline Jan & 0.72 & 0.02 & & 0.98 & 0.04 & & 1.17 & 0.03 \\
Feb & 0.71 & 0.02 & & 1.08 & 0.03 & & 1.17 & 0.03 \\
Mar & 0.92 & 0.02 & & 1.03 & 0.48 & & 1.20 & 0.02 \\
Apr & 0.72 & 0.02 & & 0.87 & 0.48 & & 1.29 & 0.21 \\
May & 0.61 & 0.02 & & 0.89 & 0.73 & & 1.55 & 0.03 \\
Jun & 0.83 & 0.02 & & 0.94 & 0.74 & & 1.64 & 0.04 \\
Jul & 0.75 & 0.02 & & 1.18 & 0.82 & & 1.73 & 0.04 \\
Aug & 0.79 & 0.03 & & 1.08 & 0.77 & & 1.75 & 0.03 \\
Sep & 0.69 & 0.02 & & 1.07 & 0.04 & & 1.36 & 0.23 \\
Oct & 0.70 & 0.02 & & 0.92 & 0.03 & & 1.18 & 0.02 \\
Nov & 0.84 & 0.01 & & 1.12 & 0.93 & & 1.23 & 0.04 \\
Dec & 0.96 & 0.01 & & 1.46 & 0.03 & & 1.42 & 0.03 \\
\hline
\end{tabular}

measurements is also clear in several cases (temperatures at $0.5^{\circ} \mathrm{C}$ intervals, 19J04, 26I02, 04F01, 06 N01, 24F01, and 20C01). The absence of temperatures below $0^{\circ} \mathrm{C}$ is also noteworthy (for $\mathrm{TN}$ at $30 \mathrm{~F} 01$ and 26I02). Therefore, it can be stated that the poor quality of some observed temperatures may underlie the lowest agreements with the gridded dataset, rather than revealing a limitation of the dataset itself.

With regard to the coherence with other datasets, the above-presented temperature patterns (Fig. 3) are in overall agreement with previous studies (Costa et al. 2017; Santos et al. 2017), using well-documented datasets, such as the WorldClim dataset (Hijmans et al. 2005) and the Climatic Digital Atlas for the Iberian Peninsula (Ninyerola et al. 2005). The WorldClim dataset provides long-term monthly means of TG, TN, and TX, for the period of 1970-2000, and has been widely applied in Portugal (Fraga et al. 2014). However, a comparative analysis reveals some important discrepancies between the present study TG dataset and WorldClim TG (supplemental Figs. S3 and S4), particularly over northern Portugal. In fact, the wintertime west-east TG gradient over northern Portugal is clearly underestimated by WorldClim, as well as summer-autumn temperatures in northeastern Portugal. WorldClim also overestimates the vertical temperature gradient in the area of Serrada-Estrela (the highest mountain in central Portugal; cf. Fig. 2). Part of these inconsistencies can be explained by the bias corrections carried out to improve the correspondence between the interpolated fields and local meteorological observations, which implicitly take into account mesoscale features that may also be relevant to local climates (e.g., breeze systems, thermal inversions, and land cover). Further, the present study geostatistical approach is based on regional statistical relationships between predictors and predictands (estimated only for mainland Portugal), instead of being estimated on a large scale that may not take into account the Portuguese climate specificities. Similar considerations can be made for TN and TX (not shown).

A consistency analysis for the nine temperature indices (TGa, TNa, TXa, TNn, TXx, SU, CSU, FD, and TR), defined at the annual time scale, calculated both at six meteorological stations in Portugal (Beja, Bragança, Coimbra, Lisboa, Porto, and Tavira; cf. Fig. 2) and at the nearest points from PT.TG/TN/TX.HRES, shows good agreement (Table 3 ). Time series were first linearly detrended in order to remove the effects of long-term trends. The $R^{2}$ values are generally satisfactory, with values above 0.8 for TGa, TNa, TXa, TNn, and TXx. The lowest values are observed for CSU in Tavira (0.24) and TR in Coimbra (0.29). Nonetheless, statistically significant correspondences were found for all indexstation pairs, at least at the $99 \%$ confidence level. RMSE values are particularly low, except for CSU, with the highest value for Beja (23 days). A dimensioned measure criterion is also shown [i.e., the mean absolute error (MAE)]. The highest value of MAE is observed for $\mathrm{TNa}\left(0.67^{\circ} \mathrm{C}\right)$ and the lowest for TGa $\left(0.07^{\circ} \mathrm{C}\right)$. For the extremes, the highest value is observed for TXx $\left(1.02^{\circ} \mathrm{C}\right)$ and the lowest for $\mathrm{TNn}\left(0.27^{\circ} \mathrm{C}\right)$. These outcomes highlight a satisfactory agreement between the database and the data recorded at the six stations.

\section{Summary and conclusions}

A two-step approach was followed for developing high-resolution $(\sim 1 \mathrm{~km})$ daily mean, minimum, and maximum temperatures over mainland Portugal (PT.TG.HRES, PT.TN.HRES, and PT.TX.HRES) over the period of 1950-2015 (66 yr). A gridded daily temperature dataset (E-OBS) at an $\sim 25-\mathrm{km}$ grid was the basis of this approach. As previously mentioned, these gridded datasets were used instead of the original weather station records, owing to the low-density weather station network in Portugal, also with significant data gaps and data inhomogeneities. A geostatistical methodology, using elevation, distance to coastline, and latitude, was used for resolving the spatial variability of temperatures in Portugal. This methodology also incorporated a postprocessing bias correction (by a kriging of residuals), based on the monthly baseline normals for 36 reference weather stations throughout Portugal. This technique led to a more accurate dataset with respect to local data, such as by integrating underlying nonlinear predictor-predictand relationships that are not taken 

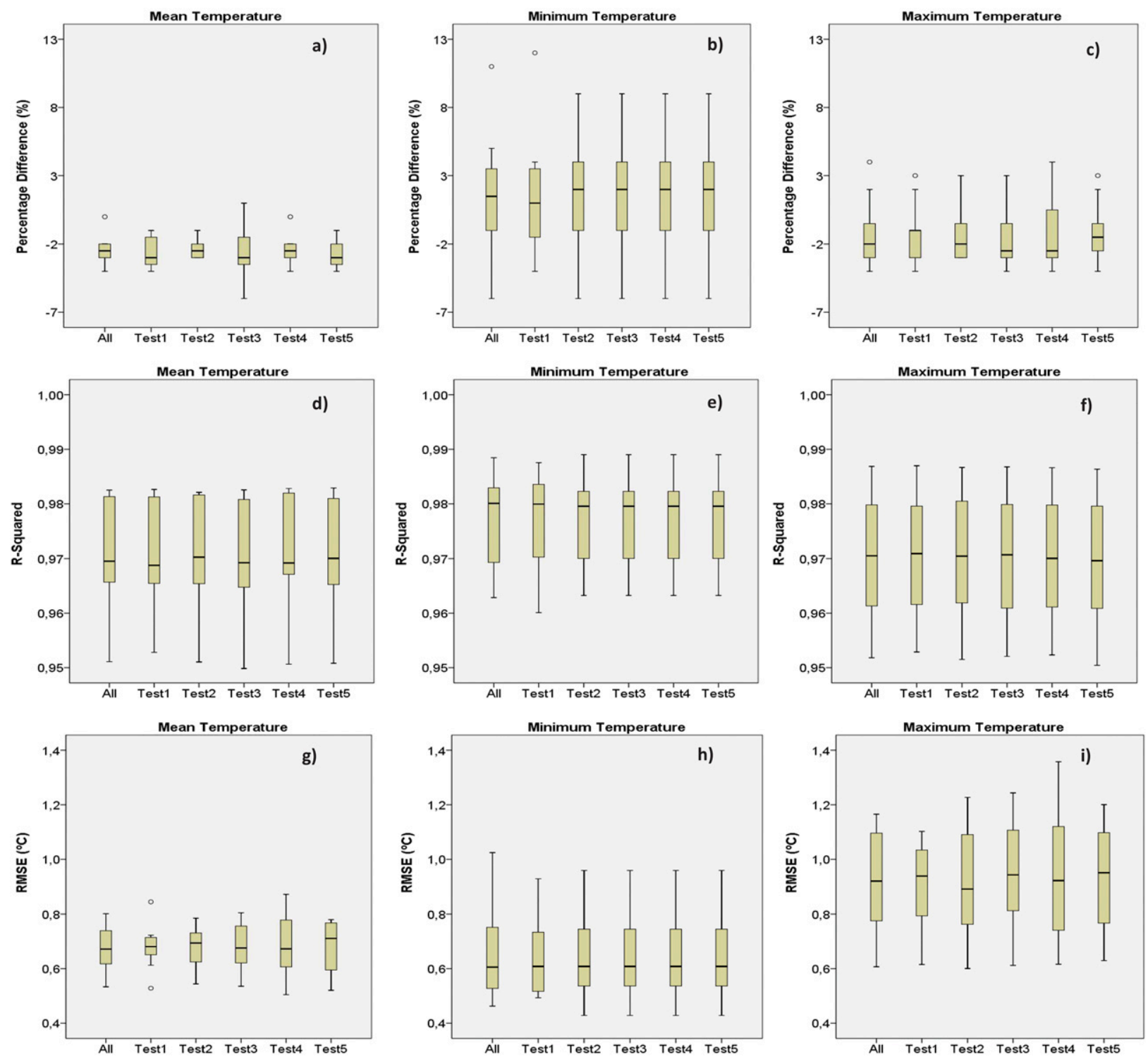

FIG. 8. Box plots of the downscaling performance measures for (left) PT.TG.HRES, (center) PT.TN.HRES, and (right) PT.TX.HRES, calculated on a monthly basis for the 36 weather stations (cf. Fig. 2): (a)-(c) percentage difference, (d)-(f) $R^{2}$, and (g)-(i) RMSE ( $\left.{ }^{\circ} \mathrm{C}\right)$. These measures are shown for the full dataset (All) and for five different tests (labeled Test 1-Test 5) from a fivefold station cross-validation. Box lower (upper) limits correspond to 25th (75th) percentiles, while lower (upper) whiskers correspond to nonoutlier minima (maxima). Outliers are values outside the range of [ 25 th percentile -1.5 box height, 75 th percentile +1.5 box height]. Medians are horizontal lines within each box.

into account by multivariate linear regressions (e.g., the elevation-temperature relationship is not strictly linear), as well as other factors controlling temperatures at local-to-regional scales (e.g., mesoscale processes, land cover parameters, and local physiographic features). The temporal variability was resolved by the bilinearly interpolated daily temperature anomalies, under the assumption that they are strongly controlled by largescale atmospheric circulation and thus tend to present high spatial coherency. This assumption was generally supported by the validation analysis of the datasets.
A cross-validation method was conducted to assess the method performance, revealing an overall high skill of the datasets in reproducing observed temperatures throughout the country. A general comparison with existing datasets also shows relatively high coherency, despite some important discrepancies, such as a noteworthy underestimation of summertime temperatures in the upper Douro Valley by the WorldClim dataset. This region, in particular, is a renowned winemaking region (Port-Douro wine region) and an accurate characterization of the climatic conditions is of foremost 
TABLE 2. The $R^{2}$ values between daily temperatures (TG, TN, and TX) recorded at 16 weather stations in Portugal (cf. Fig. 2) and the corresponding near-point grid values from PT.TG.HRES, PT.TN.HRES, and PT.TX.HRES, respectively. The individual scatterplots are shown in supplemental Fig. S5.

\begin{tabular}{|c|c|c|c|c|c|c|c|c|c|c|}
\hline \multirow[b]{2}{*}{ Station code } & \multirow[b]{2}{*}{ Period } & \multicolumn{3}{|c|}{$R^{2}(\%)$} & \multicolumn{3}{|c|}{$\operatorname{MAE}\left({ }^{\circ} \mathrm{C}\right)$} & \multicolumn{3}{|c|}{$\mathrm{RMSE}\left({ }^{\circ} \mathrm{C}\right)$} \\
\hline & & $\mathrm{TG}$ & $\mathrm{TN}$ & TX & TG & $\mathrm{TN}$ & $\mathrm{TX}$ & $\mathrm{TG}$ & $\mathrm{TN}$ & $\mathrm{TX}$ \\
\hline 04N01 & $2003-15$ & 96 & 93 & 94 & 1.36 & 1.40 & 1.54 & 1.78 & 1.78 & 2.15 \\
\hline $19 \mathrm{~J} 04$ & $2001-15$ & 95 & 95 & 97 & 1.33 & 1.01 & 2.16 & 1.62 & 1.72 & 3.01 \\
\hline $26 \mathrm{I} 02$ & $2001-15$ & 94 & 87 & 87 & 1.76 & 1.34 & 1.63 & 2.10 & 1.96 & 2.16 \\
\hline $19 \mathrm{O} 02$ & $2001-15$ & 96 & 97 & 89 & 1.06 & 1.33 & 1.19 & 1.34 & 1.92 & 1.62 \\
\hline $17 \mathrm{H} 01$ & $2001-15$ & 93 & 80 & 89 & 1.51 & 3.46 & 3.56 & 1.86 & 4.57 & 5.02 \\
\hline $30 \mathrm{~F} 01$ & 1984-2015 & 79 & 67 & 86 & 2.10 & 2.41 & 1.84 & 3.06 & 2.99 & 2.38 \\
\hline 06N01 & 1981-2015 & 91 & 85 & 89 & 1.82 & 1.76 & 2.32 & 2.34 & 2.28 & 3.11 \\
\hline 30E03 & $2001-15$ & 92 & 85 & 85 & 1.07 & 1.49 & 1.95 & 1.36 & 1.98 & 2.46 \\
\hline $22 \mathrm{~F} 03$ & 1956-2015 & 92 & 83 & 92 & 1.26 & 1.58 & 1.43 & 1.70 & 2.19 & 2.09 \\
\hline $16 \mathrm{C} 01$ & $2001-15$ & 74 & 70 & 68 & 1.92 & 2.34 & 2.58 & 2.45 & 2.84 & 3.55 \\
\hline 04F01 & 1981-2015 & 91 & 88 & 92 & 1.33 & 1.28 & 1.33 & 1.71 & 1.87 & 1.71 \\
\hline 03G02 & $2003-15$ & 90 & 86 & 92 & 1.56 & 1.55 & 1.46 & 1.95 & 1.98 & 1.91 \\
\hline 26M01 & 1969-2015 & 95 & 88 & 94 & 1.17 & 1.77 & 1.28 & 1.53 & 2.24 & 1.97 \\
\hline 08G01 & 1982-2015 & 88 & 79 & 85 & 1.49 & 1.59 & 2.25 & 1.91 & 2.19 & 2.91 \\
\hline $20 \mathrm{C} 01$ & 1970-2013 & 91 & 80 & 88 & 1.27 & 2.01 & 1.68 & 1.65 & 2.65 & 2.34 \\
\hline 24F01 & 1982-2015 & 92 & 78 & 94 & 1.38 & 2.10 & 1.42 & 1.77 & 2.80 & 1.93 \\
\hline
\end{tabular}

relevance for regional wine producers and wineries, for example, by providing them precise information generated by grapevine modeling and bioclimatic zoning (Fraga et al. 2016a; Fraga and Santos 2017). These misrepresentations of local-to-regional climates may arise when datasets are not developed within an arealimited sector that properly takes into account regional climatic features (Giorgi and Mearns 1999).
These new high-resolution climatological datasets over Portugal were analyzed in terms of average fields, seasonality, interannual variability, long-term trends, and extremes. The results allow a detailed analysis of the air temperature conditions in Portugal, at an unprecedented high spatial resolution of $\sim 1 \mathrm{~km}$. Furthermore, in agreement with several previous studies, long-term warming trends are quite clear throughout the country and are also

TABLE 3. The $R^{2}$, RMSE, and MAE values of the selected climatic parameters (TGa, TNa, TXa, TXx, TNn, SU, CSU, FD, and TR) between the E-OBS database and the new very-high-resolution temperature databases at six meteorological stations (Beja, Bragança, Coimbra, Lisboa, Porto, and Tavira; cf. Fig. 2).

\begin{tabular}{|c|c|c|c|c|c|c|c|c|c|}
\hline & $\mathrm{TGa}$ & $\mathrm{TNa}$ & $\mathrm{TXa}$ & $\mathrm{TNn}$ & $\mathrm{TXx}$ & SU & CSU & FD & TR \\
\hline \multicolumn{10}{|l|}{$R^{2}(\%)$} \\
\hline Beja & 99 & 82 & 99 & 86 & 83 & 94 & 33 & 79 & 75 \\
\hline Bragança & 99 & 99 & 99 & 99 & 99 & 94 & 86 & 72 & 71 \\
\hline Coimbra & 99 & 99 & 99 & 80 & 99 & 99 & 75 & 67 & 29 \\
\hline Lisboa & 99 & 99 & 99 & 99 & 99 & 82 & 65 & 83 & 60 \\
\hline Porto & 99 & 95 & 99 & 75 & 99 & 94 & 63 & 64 & 77 \\
\hline Tavira & 99 & 99 & 99 & 99 & 99 & 92 & 24 & 90 & 82 \\
\hline \multicolumn{10}{|l|}{$\operatorname{RMSE}\left({ }^{\circ} \mathrm{C}\right)$} \\
\hline Beja & 0.49 & 0.27 & 0.10 & 0.97 & 1.49 & 5.24 & 23.06 & 1.01 & 3.91 \\
\hline Bragança & 0.28 & 0.28 & 0.13 & 1.26 & 0.92 & 2.94 & 5.39 & 9.89 & 1.39 \\
\hline Coimbra & 0.07 & 0.85 & 0.26 & 0.61 & 1.82 & 7.43 & 5.99 & 2.77 & 2.34 \\
\hline Lisboa & 0.45 & 0.46 & 0.28 & 0.83 & 1.45 & 6.60 & 7.85 & 0.12 & 4.98 \\
\hline Porto & 0.50 & 0.18 & 0.21 & 0.64 & 2.28 & 5.66 & 2.74 & 3.01 & 0.80 \\
\hline Tavira & 0.17 & 0.26 & 0.12 & 0.55 & 1.19 & 8.49 & 21.40 & 0.39 & 5.28 \\
\hline \multicolumn{10}{|l|}{$\operatorname{MAE}\left({ }^{\circ} \mathrm{C}\right)$} \\
\hline Beja & 0.60 & 0.20 & 0.08 & 0.92 & 1.50 & 4.67 & 17.24 & 0.67 & 3.58 \\
\hline Bragança & 0.35 & 0.17 & 0.14 & 1.02 & 0.89 & 3.50 & 4.65 & 4.91 & 0.78 \\
\hline Coimbra & 0.07 & 0.67 & 0.27 & 0.56 & 1.87 & 8.79 & 4.72 & 2.56 & 1.96 \\
\hline Lisboa & 0.33 & 0.23 & 0.18 & 0.60 & 1.16 & 5.13 & 5.35 & 0.02 & 3.22 \\
\hline Porto & 0.52 & 0.13 & 0.18 & 0.50 & 2.43 & 6.26 & 2.21 & 2.51 & 0.57 \\
\hline Tavira & 0.15 & 0.25 & 0.09 & 0.45 & 1.06 & 8.68 & 20.30 & 0.23 & 5.66 \\
\hline
\end{tabular}


manifested in the different temperature indices, although spatial heterogeneities deserve further research in forthcoming studies. The datasets produced within the present study can be applied to a wide range of areas of research such as hydrology and agricultural and forestry systems, which have been shown to be under pressure by climate change projections in Portugal (Costa et al. 2017; Fonseca et al. 2015; Fraga et al. 2016b,c; Santos et al. 2017). The resulting knowledge can inform decision support systems to provide more reliable and accurate guidelines to stakeholders and policymakers of economically relevant socioeconomic sectors in Portugal.

Acknowledgments. This study was funded by the "Integrative Research in Environment, Agro-Chains and Technology" project (INTERACT; NORTE-010145-FEDER-000017) in its line of research entitled BEST-T4, cofinanced by the European Regional Development Fund (ERDF) through NORTE 2020 (North Regional Operational Program 2014/2020). It was also supported by FEDER/COMPETE/POCI (Operational Competitiveness and Internationalization Programme), POCI-01-0145-FEDER-006958, and by FCT (Portuguese Foundation for Science and Technology), UID/AGR/04033/2013. We acknowledge the E-OBS dataset from the EU-FP6 project ENSEMBLES (http://ensembles-eu.metoffice.com) and the data providers in the ECA\&D project (http://www.ecad.eu)

\section{REFERENCES}

Ahmed, K., S. Shahid, and S. Bin Harun, 2015: Statistical downscaling of rainfall in an arid coastal region: A radial basis function neural network approach. Appl. Mech. Mater., 735, 190-194, https://doi.org/10.4028/www.scientific.net/ AMM.735.190.

Andrade, C., S. M. Leite, and J. A. Santos, 2012: Temperature extremes in Europe: Overview of their driving atmospheric patterns. Nat. Hazards Earth Syst. Sci., 12, 1671-1691, https:// doi.org/10.5194/nhess-12-1671-2012.

_ H. Fraga, and J. A. Santos, 2014: Climate change multi-model projections for temperature extremes in Portugal. Atmos. Sci. Lett., 15, 149-156, https://doi.org/10.1002/asl2.485.

Beldring, S., T. Engen-Skaugen, E. J. Førland, and L. A. Roald, 2008: Climate change impacts on hydrological processes in Norway based on two methods for transferring regional climate model results to meteorological station sites. Tellus, $60 \mathbf{A}$, 439-450, https://doi.org/10.1111/j.1600-0870.2008.00306.x.

CDO, 2015: Climate data operators. Max Planck Institute for Meteorology, http://www.mpimet.mpg.de/cdo.

Chen, J., F. P. Brissette, D. Chaumont, and M. Braun, 2013: Finding appropriate bias correction methods in downscaling precipitation for hydrologic impact studies over North America. Water Resour. Res., 49, 4187-4205, https://doi.org/10.1002/ wrcr.20331.

Chu, J.-L., H. Kang, C.-Y. Tam, C.-K. Park, and C.-T. Chen, 2008: Seasonal forecast for local precipitation over northern Taiwan using statistical downscaling. J. Geophys. Res., 113, D12118, https://doi.org/10.1029/2007JD009424.

Costa, R., H. Fraga, P. M. Fernandes, and J. A. Santos, 2017: Implications of future bioclimatic shifts on Portuguese forests. Reg. Environ. Change, 17, 117-127, https://doi.org/10.1007/ s10113-016-0980-9.

Daly, C., W. P. Gibson, G. H. Taylor, G. L. Johnson, and P. Pasteris, 2002: A knowledge-based approach to the statistical mapping of climate. Climate Res., 22, 99-113, https:// doi.org/10.3354/cr022099.

Dee, D. P., and Coauthors, 2011: The ERA-Interim reanalysis: Configuration and performance of the data assimilation system. Quart. J. Roy. Meteor. Soc., 137, 553-597, https://doi.org/ 10.1002/qj.828.

De Smith, M. J., M. F. Goodchild, and P. A. Longley, 2007: Geospatial Analysis: A Comprehensive Guide to Principles, Techniques and Software Tools. Troubador Publishing, 394 pp.

Di Luzio, M., G. L. Johnson, C. Daly, J. K. Eischeid, and J. G. Arnold, 2008: Constructing retrospective gridded daily precipitation and temperature datasets for the conterminous United States. J. Appl. Meteor. Climatol., 47, 475-497, https:// doi.org/10.1175/2007JAMC1356.1.

Dobler, C., S. Hagemann, R. L. Wilby, and J. Stötter, 2012: Quantifying different sources of uncertainty in hydrological projections in an Alpine watershed. Hydrol. Earth Syst. Sci., 16, 4343-4360, https://doi.org/10.5194/hess-16-4343-2012.

Duchon, C. E., 1979: Lanczos filtering in one and two dimensions. J. Appl. Meteor., 18, 1016-1022, https://doi.org/10.1175/ 1520-0450(1979)018<1016:LFIOAT > 2.0.CO;2.

Espírito Santo, F., M. I. P. de Lima, A. M. Ramos, and R. M. Trigo, 2014: Trends in seasonal surface air temperature in mainland Portugal, since 1941. Int. J. Climatol., 34, 1814-1837, https:// doi.org/10.1002/joc.3803.

Fonseca, A., C. Botelho, R. A. R. Boaventura, and V. J. P. Vilar, 2015: Global warming effects on faecal coliform bacterium watershed impairments in Portugal. River Res. Appl., 31, 1344-1353, https://doi.org/10.1002/rra.2821.

Fraga, H., and J. A. Santos, 2017: Daily prediction of seasonal grapevine production in the Douro wine region based on favourable meteorological conditions. Aust.J. Grape Wine Res., 23, 296-304, https://doi.org/10.1111/ajgw.12278.

— A. C. Malheiro, J. Moutinho-Pereira, G. V. Jones, F. Alves, J. G. Pinto, and J. A. Santos, 2014: Very high resolution bioclimatic zoning of Portuguese wine regions: Present and future scenarios. Reg. Environ. Change, 14, 295-306, https://doi.org/ 10.1007/s10113-013-0490-y.

_ I. García de Cortázar Atauri, A. C. Malheiro, and J. A. Santos, 2016a: Modelling climate change impacts on viticultural yield, phenology and stress conditions in Europe. Global Change Biol., 22, 3774-3788, https://doi.org/10.1111/ gcb.13382.

_ J. A. Santos, A. C. Malheiro, A. A. Oliveira, J. MoutinhoPereira, and G. V. Jones, 2016b: Climatic suitability of Portuguese grapevine varieties and climate change adaptation. Int. J. Climatol., 36, 1-12, https://doi.org/10.1002/joc.4325.

$\longrightarrow,-$ J. Moutinho-Pereira, C. Carlos, J. Silvestre, J. EirasDias, T. Mota, and A. C. Malheiro, 2016c: Statistical modelling of grapevine phenology in Portuguese wine regions: Observed trends and climate change projections. J. Agric. Sci., 154, 795811, https://doi.org/10.1017/S0021859615000933.

Frías, M. D., E. Zorita, J. Fernández, and C. Rodríguez-Puebla, 2006: Testing statistical downscaling methods in simulated 
climates. Geophys. Res. Lett., 33, L19807, https://doi.org/ 10.1029/2006GL027453.

Giorgi, F., and L. O. Mearns, 1999: Introduction to special section: Regional climate modeling revisited. J. Geophys. Res., 104, 6335-6352, https://doi.org/10.1029/98JD02072.

Graham, L. P., J. Andréasson, and B. Carlsson, 2007: Assessing climate change impacts on hydrology from an ensemble of regional climate models, model scales and linking methodsA case study on the Lule River basin. Climatic Change, 81, 293-307, https://doi.org/10.1007/s10584-006-9215-2.

Gutiérrez, J. M., D. San-Martín, S. Brands, R. Manzanas, and S. Herrera, 2013: Reassessing statistical downscaling techniques for their robust application under climate change conditions. J. Climate, 26, 171-188, https://doi.org/10.1175/ JCLI-D-11-00687.1.

Harris, I., P. D. Jones, T. J. Osborn, and D. H. Lister, 2014: Updated high-resolution grids of monthly climatic observations-The CRU TS3.10 dataset. Int. J. Climatol., 34, 623-642, https://doi.org/10.1002/joc.3711.

Haylock, M. R., N. Hofstra, A. M. G. Klein Tank, E. J. Klok, P. D. Jones, and M. New, 2008: A European daily high-resolution gridded data set of surface temperature and precipitation for 1950-2006. J. Geophys. Res., 113, D20119, https://doi.org/ 10.1029/2008JD010201.

Hijmans, R. J., S. E. Cameron, J. L. Parra, P. G. Jones, and A. Jarvis, 2005: Very high resolution interpolated climate surfaces for global land areas. Int. J. Climatol., 25, 1965-1978, https://doi.org/10.1002/joc.1276.

Hofstra, N., M. Haylock, M. New, and P. D. Jones, 2009: Testing E-OBS European high-resolution gridded data set of daily precipitation and surface temperature. J. Geophys. Res., 114, D21101, https://doi.org/10.1029/2009JD011799.

Klein Tank, A. M. G., and G. P. Können, 2003: Trends in indices of daily temperature and precipitation extremes in Europe, 1946-99. J. Climate, 16, 3665-3680, https://doi.org/10.1175/ 1520-0442(2003)016<3665:TIIODT >2.0.CO;2.

— air temperature and precipitation series for the European Climate Assessment. Int. J. Climatol., 22, 1441-1453, https:// doi.org/10.1002/joc.773.

Laflamme, E. M., E. Linder, and Y. Pan, 2016: Statistical downscaling of regional climate model output to achieve projections of precipitation extremes. Wea. Climate Extremes, 12, 15-23, https://doi.org/10.1016/j.wace.2015.12.001.

Laslett, G. M., 1994: Kriging and splines: An empirical comparison of their predictive performance in some applications. J. Amer. Stat. Assoc., 89, 391-400, https://doi.org/10.1080/ 01621459.1994.10476759.

Lenderink, G., A. Buishand, and W. van Deursen, 2007: Estimates of future discharges of the river Rhine using two scenario methodologies: Direct versus delta approach. Hydrol. Earth. Syst. Sci., 11, 1145-1159, https://doi.org/10.5194/ hess-11-1145-2007.

Lewis, S. C., and A. D. King, 2017: Evolution of mean, variance and extremes in 21st century temperatures. Wea. Climate Extremes, 15, 1-10, https://doi.org/10.1016/j.wace.2016.11.002.

Li, H., J. Sheffield, and E. F. Wood, 2010: Bias correction of monthly precipitation and temperature fields from Intergovernmental Panel on Climate Change AR4 models using equidistant quantile matching. J. Geophys. Res., 115, D10101, https://doi.org/10.1029/2009JD012882.

Maraun, D., and Coauthors, 2010: Precipitation downscaling under climate change: Recent developments to bridge the gap be- tween dynamical models and the end user. Rev. Geophys., 48 , RG3003, https://doi.org/10.1029/2009RG000314.

, and Coauthors, 2015: VALUE: A framework to validate downscaling approaches for climate change studies. Earth's Future, 3, 1-14, https://doi.org/10.1002/2014EF000259.

Markatou, M., H. Tian, S. Biswas, and G. Hripcsak, 2005: Analysis of variance of cross-validation estimators of the generalization error. J. Mach. Learn. Res., 6, 1127-1168.

Martin-Vide, J., 2004: Spatial distribution of a daily precipitation concentration index in peninsular Spain. Int. J. Climatol., 24, 959-971, https://doi.org/10.1002/joc.1030.

Menzel, L., and G. Bürger, 2002: Climate change scenarios and runoff response in the Mulde catchment (southern Elbe, Germany). J. Hydrol., 267, 53-64, https://doi.org/10.1016/ S0022-1694(02)00139-7.

Merino, A., M. Fernández-Vaquero, L. López, S. FernándezGonzález, L. Hermida, J. L. Sánchez, E. García-Ortega, and E. Gascón, 2016: Large-scale patterns of daily precipitation extremes on the Iberian Peninsula. Int. J. Climatol., 36, 3873 3891, https://doi.org/10.1002/joc.4601.

Monteiro-Henriques, T., M. J. Martins, J. O. Cerdeira, P. Silva, P. Arsénio, Á. Silva, A. Bellu, and J. C. Costa, 2016: Bioclimatological mapping tackling uncertainty propagation: Application to mainland Portugal. Int. J. Climatol., 36, 400411, https://doi.org/10.1002/joc.4357.

New, M., D. Lister, M. Hulme, and I. Makin, 2002: A highresolution data set of surface climate over global land areas. Climate Res., 21, 1-25, https://doi.org/10.3354/ cr021001.

Ninyerola, M., X. Pons, and J. M. Roure, 2005: Atlas Climático Digital de la Península Ibérica. Metodología y Aplicaciones en Bioclimatología y Geobotánica. Universidad Autónoma de Barcelona, $44 \mathrm{pp}$

Pareeth, S., and Coauthors, 2017: Warming trends of perialpine lakes from homogenised time series of historical satellite and in-situ data. Sci. Total Environ., 578, 417-426, https://doi.org/ 10.1016/j.scitotenv.2016.10.199.

Peixoto, J. P., and A. H. Oort, 1992: Physics of Climate. American Institute of Physics, 520 pp.

Price, D. T., D. W. McKenney, I. A. Nalder, M. F. Hutchinson, and J. L. Kesteven, 2000: A comparison of two statistical methods for spatial interpolation of Canadian monthly mean climate data. Agric. For. Meteor., 101, 81-94, https://doi.org/10.1016/ S0168-1923(99)00169-0.

Santos, J. A., and J. Corte-Real, 2006: Temperature extremes in Europe and wintertime large-scale atmospheric circulation: HadCM3 future scenarios. Climate Res., 31, 3-18, https:// doi.org/10.3354/cr031003.

— M. F. Carneiro, A. Correia, M. J. Alcoforado, E. Zorita, and J. J. Gómez-Navarro, 2015a: New insights into the reconstructed temperature in Portugal over the last 400 years. Climate Past, 11, 825-834, https://doi.org/10.5194/cp-11-825-2015.

- S. Pfahl, J. G. Pinto, and H. Wernli, 2015b: Mechanisms underlying temperature extremes in Iberia: A Lagrangian perspective. Tellus, 67A, 26032, https://doi.org/10.3402/tellusa. v67.26032.

Santos, M., J. A. Santos, and M. Fragoso, 2017: Atmospheric driving mechanisms of flash floods in Portugal. Int. J. Climatol., 37, 671-680, https://doi.org/10.1002/ joc. 5030 .

Schamm, K., M. Ziese, A. Becker, P. Finger, A. Meyer-Christoffer, U. Schneider, M. Schröder, and P. Stender, 2014: Global gridded precipitation over land: A description of the new 
GPCC First Guess Daily product. Earth Syst. Sci. Data, 6, 49-60, https://doi.org/10.5194/essd-6-49-2014.

Schuurmans, J. M., M. F. P. Bierkens, E. J. Pebesma, and R. Uijlenhoet, 2007: Automatic prediction of high-resolution daily rainfall fields for multiple extents: The potential of operational radar. J. Hydrometeor., 8, 1204-1224, https://doi.org/ 10.1175/2007JHM792.1.

Solman, S. A., 2013: Regional climate modeling over South America: A review. Adv. Meteor., 2013, 504357, https:// doi.org/10.1155/2013/504357.
Vrac, M., M. L. Stein, K. Hayhoe, and X.-Z. Liang, 2007: A general method for validating statistical downscaling methods under future climate change. Geophys. Res. Lett., 34, L18701, https:// doi.org/10.1029/2007GL030295.

Washington, W. M., and C. L. Parkinson, 2005: An Introduction to ThreeDimensional Climate Modeling. University Science Books, 353 pp.

Willmott, C. J., and S. M. Robeson, 1995: Climatologically aided interpolation (CAI) of terrestrial air temperature. Int. J. Climatol., 15, 221-229, https://doi.org/10.1002/joc. 3370150207. 